\title{
Preparing black raspberry components for their use as cancer therapeutics
}

\author{
Daniel S. Peiffer* \\ Loyola University Chicago, Health Sciences Division, Maywood, Illinois
}

Received 1 November 2018; accepted 3 November 2018

\begin{abstract}
Black raspberries (BRB) have been shown to inhibit the progression of a number of cancers including breast, esophageal, colon, and oral cancers both in preclinical models. These results have led to further clinical evaluation for the use of BRB in the prevention of cancer onset in high risk populations as well as preventing its further progression. However, the use of BRB as a cancer therapy can be challenging due to variability in nutritional content of BRB lots and differences in patient metabolism of the active BRB components. Thus, the preparation of fractions possessing enriched amounts of the active constituents of BRB may improve patients' access to the anti-cancer benefits afforded by BRB, and ultimately improve clinical outcomes. These components of BRB include anthocyanins, protocatechuic acid, quercetin, ellagic acid, all of which have exhibited anti-cancer properties. Which treatment modality and its method of delivery is most efficacious in the context of cancer therapy has yet to be definitively realized. Improvements in BRB fractionation as well as enhanced delivery of these BRB components to target tissues off promising results. Together these advancements may improve their efficacy as cancer therapeutics, and thus allow for more treatment modalities in cancer therapy.
\end{abstract}

Keywords: Cancer prevention, black raspberry, anthocyanins, protocatechuic acid, human clinical trial

\section{Introduction}

As of today, extensive evidence exists for the use of plant-based diets in the prevention and treatment of cancer in human subjects. This includes population health statistics indicating a decreased risk of cancer with increased intake of dietary fruits and vegetables [1-4]. This is thought to be due to the high amounts of vitamins, minerals, dietary fiber, and phenolic compounds that have been shown to possess anti-cancer properties [5]. The use of BRB specifically in the prevention of cancer onset and/or as a treatment of cancer have been studied extensively in preclinical models and human subjects. This includes preclinical animal models which report that BRB inhibit the progression of esophageal, colon, breast and oral cancer namely through the specific targeting of tumor cell proliferation, angiogenesis, apoptosis and immune cell trafficking within the tumor microenvironment [5-17]. These results have correlated with the prevention and treatment of cancer in human subjects through the use of BRB [18-26]. Although the mechanisms as to how BRB have been protective in these preclinical models and human trials is well documented, until recently, the specific molecular components of BRB that induce these anticancer effects was less understood. These include the identification and testing of individual components of BRB including polyphenolic anthocyanins [27] and their active metabolite protocatechuic acid (PCA) [10], as well as other components of BRB including ellagic acid [8], and quercetin [28]. Advancements in the quantification

\footnotetext{
${ }^{*}$ Corresponding author: Daniel S. Peiffer, MD/PhD Program, Loyola University Chicago, Health Sciences Division, Maywood, Illinois. E-mail: dpeiffer1@luc.edu.
} 
Table 1

Ongoing clinical trials of BRB and its constituents

\begin{tabular}{|c|c|c|c|c|c|}
\hline $\begin{array}{l}\text { Population, } \\
\text { no. patients }\end{array}$ & $\begin{array}{l}\text { Clinical trial } \\
\text { identifier }\end{array}$ & $\begin{array}{l}\text { Agent Used } \\
\text { (Delivery } \\
\text { method) }\end{array}$ & $\begin{array}{l}\text { Study } \\
\text { duration }\end{array}$ & Location & $\begin{array}{l}\text { Endpoint } \\
\text { measurements }\end{array}$ \\
\hline $\begin{array}{l}\text { Prostate cancer } \\
(n=56)\end{array}$ & NCT01823562 & $\begin{array}{l}\text { BRB (Daily oral } \\
\text { intake of } \\
\text { freeze-dried } \\
\text { powder) }\end{array}$ & $\begin{array}{l}6 \text { weeks } \\
\text { post-surgery }\end{array}$ & $\begin{array}{l}\text { Arthur G. James Cancer } \\
\text { Hospital and Solove } \\
\text { Research Institute at Ohio } \\
\text { State University Medical } \\
\text { Center }\end{array}$ & $\begin{array}{l}\text { Lesion size and } \\
\text { histopathology, GF-1, } \\
\text { IGF-BP3, PTEN, } \\
\text { phosphor-AKT, } \\
\text { VEGF, PBMC levels }\end{array}$ \\
\hline $\begin{array}{l}\text { Colon cancer } \\
(n=100)\end{array}$ & NCT01948661 & $\begin{array}{l}\text { AC (Capsule } \\
\text { intake once daily) }\end{array}$ & $\begin{array}{l}4 \text { weeks } \\
\text { post-surgery }\end{array}$ & $\begin{array}{l}\text { ASL 3, Ospedale Villa } \\
\text { Scassi, S.C. } \\
\text { Gastroenterologia } \\
\text { Genova, Italy }\end{array}$ & $\begin{array}{l}\text { B-catenin, NF-K } \beta \text {, } \\
\text { Ki-67, p53 }\end{array}$ \\
\hline $\begin{array}{l}\text { Prostate cancer } \\
(n=31)\end{array}$ & NCT01912820 & $\begin{array}{l}\text { Q (Capsule intake } \\
2 \mathrm{X} \text { daily) }\end{array}$ & $\begin{array}{l}6 \text { weeks } \\
\text { post-surgery }\end{array}$ & $\begin{array}{l}\text { Jonsson Comprehensive } \\
\text { Cancer Center } \\
\text { Los Angeles, California, } \\
\text { United States }\end{array}$ & $\begin{array}{l}\text { DNMT1, MRP1, } \\
\text { COMT, PBMCs }\end{array}$ \\
\hline $\begin{array}{l}\text { Prostate cancer } \\
(n=80)\end{array}$ & NCT03535675 & $\begin{array}{l}\text { EA (Capsule } \\
\text { intake } 1 \text { daily) }\end{array}$ & 48 weeks & $\begin{array}{l}\text { Sidney Kimmel } \\
\text { Comprehensive Cancer } \\
\text { Center at Johns Hopkins }\end{array}$ & PSA slope in serum \\
\hline
\end{tabular}

$\mathrm{BRB}=$ black raspberries; $\mathrm{AC}=$ anthocyanins; $\mathrm{Q}=$ quercetin $; \mathrm{EA}=$ Ellagic acid.

and preparation of these individual components has facilitated their use in cancer research and opens the door for their further use in a human clinical trial setting.

A thorough search using PubMed was conducted on articles published through October 31st, 2018 to identify all preclinical and human trials using BRB and/or their constituents in the prevention or treatment of cancer. Keywords used in this search included black raspberries, cancer, premalignant, anthocyanins, protocatechuic acid, PCA, ellagic acid, quercetin, and clinical trials. Studies comparing the use of BRB vs. constituents in preclinical and human trials were reviewed. Each individual clinical trial and its details are reported and referenced in the sections summarizing BRB and their individual components of interest. Ongoing human clinical trials used BRB and their components are shown in Table 1.

\section{Results}

\subsection{Use of whole BRB in human clinical trials}

The use of BRB in the prevention of esophageal cancer onset in a high-risk population (Barrett's esophagus patients) has been investigated extensively [21]. Barrett's esophagus is classified as an inflammatory disease of the esophagus, and is the only known precursor lesion to esophageal adenocarcinoma, a subtype of esophageal cancer [29]. Due to the known anti-inflammatory effects of BRB, it was investigated whether BRB could prevent the progression of the disease to esophageal cancer $[6,10,12,16,17]$. Patients 18 years old or older with a clinical diagnosis of Barrett's esophagus were given 32 (female) or 45 (male) grams (based on average body weight) of BRB powder once/day mixed in water [21]. Urinary levels of oxidative DNA damaged and lipid peroxidation were measured, and specifically expression of 8-Prostaglandin F2 $\alpha$ was reduced, suggesting BRB 
intake reduces oxidative stress in this high-risk group of patients [21]. This was accompanied by an increase in the detoxification marker Glutathione S Transferase Pi in the esophageal epithelial in over half (55.6\%) of the patients, although the expression of proliferative marker Ki-67 was unchanged [21].

Additionally, the use of BRB in the treatment of cancer, specifically colon cancer, has also been studied in human trials. As BRB have been shown to inhibit the formation of colon tumors in preclinical models [11], it was investigated whether these effects extended to humans diagnosed with colon cancer [23]. Colonic samples were taken from patients before and after 1 to 9 weeks of oral BRB intake, taken as a powder slurry in water [23]. In patients that took the slurry 4 or more weeks, there was a significant decrease in Ki-67, CD105 (an angiogenic marker), and $\beta$-catenin (the key oncoprotein in colon cancer) expression [23], all of which are overexpressed and associated with a poorer prognosis in the disease. Taken together, these results and those reported in the Barrett's esophagus pilot study suggest BRB represent a potential therapeutic in preventing the onset and/or progression of cancer.

Recently, preclinical studies have focused on the use of BRB components, in the form of enriched extracts, in the prevention and/or treatment of cancer [10, 17, 27, 30-32]. This is for a number of reasons. Firstly, the polyphenolic components of BRB can have a high degree of variability between yields, which may in turn cause variability in objective clinical response among patients [33]. Further, patient populations can also vary in their genetic makeup and their expression of metabolic enzymes. This is illustrated in a Barrett's esophagus pilot study using BRB, in which a high degree of variation in urinary expression of ellagitannin metabolites, an anti-cancer component of BRB, was reported [21]. Thus, when giving complete BRB, only those patients that express enzymes that release these beneficial metabolites reap the benefits of BRB as a cancer therapeutic. One way to prevent the individual variation, is to standardize the therapeutic by discerning which components of BRB are beneficial, and the optimal method of delivery for these compounds. This would in turn standardize human trial studies, allowing for accurate interpretation of the effects BRB components have on human diseases like cancer.

\subsection{Preparation of BRB anthocyanin-enriched fractions for use in human clinical trials}

Anthocyanins are a group of polyphenolic compounds that are rich in BRB, accounting for up to $10 \%$ of their dry weight [30]. The use of anthocyanins in the prevention and treatment of cancers has been well characterized in preclinical models. Specifically, BRB anthocyanins have been shown to prevent and inhibit the progression of cancers of the esophagus [10, 17, 27], colon [11], breast [31], pancreatic [32], and prostate [33]. This is thought to be due to the anti-inflammatory effects by reduction of Cyclooxygenase-2 (COX2) and CD45 expression, anti-angiogenetic effects by inhibition of microvessel formation, and the induction of apoptosis of tumor cells by increasing BCL-2-associated X protein expression [10, 17, 21, 27].

To date, human cancer clinical trials involving the use of anthocyanin-enriched fractions are scarce. This is attributed to a number of factors including variability in bioactive content within each fraction preparation, as well as limitations in our ability to evaluate anthocyanin levels within human tissues and biological fluids [31-33]. Until recently, quantification of anthocyanin absorption and excretion was limited, but recent advances in liquid chromatography have allowed for the accurate measurement of anthocyanin levels in patient fluids and tissues [34]. This method was developed by Giordano et al., in which anthocyanin levels were detected in the biological fluids of 18 healthy subjects during a cardiovascular prevention phase 1 clinical trial. Specifically, anthocyanins were detected down to the nanomolar levels of concentration in both blood and urine. Thus, this method of quantification facilitates the proper evaluation of therapeutic efficacy of anthocyanin supplementation in cancer clinical trials. Further, a method developed by Kay et al. using ${ }^{13} \mathrm{C}$ labeling of the major BRB anthocyanin, cyaniding-3-glucoside (C-3-Gluc) has allowed for biological tracking of these compounds and furthered our understanding of the bioavailability of BRB anthocyanins, and their pharmacokinetics. Specifically, recent evidence suggests that anthocyanins have a much higher bioavailability than previously reported, with minimum levels approaching $12 \%$ [35, 36]. These findings not only aide in the tracking of anthocyanins to quantify tissue 
site-specific delivery, but also provide further support for the use of anthocyanins in cancer therapies, as these compounds are more readily absorbed than previously reported.

Finally, advances in BRB anthocyanin-enriched fraction preparation have allowed for increased delivery of anthocyanins to target tissues [33]. The food matrix is a known factor that influences the release, absorption and stability of anthocyanins [37]. Further, it has been reported by Walton et al. that anthocyanins in a pectin-based oatmeal matrix have a delay and reduction in absorption and ultimately secretion compared to anthocyanins in a water fraction [38]. Gu et al. have developed a method for the preparation of a BRB anthocyanin-enriched fraction in both a pectin-based and nectar (juice) preparation and have used these to evaluate anthocyanin delivery on a cohort of prostate cancer patients [33]. The method for preparations of these fractions has yielded anthocyanin retention rates of over $90 \%$ for the pectin-based preparations, asserting an efficient method of $\mathrm{BRB}$ anthocyanin fraction preparation. Conversely, the juice (nectar) preparations yielded much lower BRB anthocyanin retention rates, approaching $\sim 30 \%$ [33]. The group attributed these differences in anthocyanin retention to the mixing/heating steps between these two preparations [33]. Further, the stability of the anthocyanins was quite high in both preparations, with no significant decrease in anthocyanin content following up to 8 weeks of storage [33]. This suggests both of these fractions could be used for long-term clinical trials. Together these findings suggest a legitimate method for BRB anthocyanin-enriched fraction preparation to be used in human clinical trials.

\subsection{Use of stable BRB anthocyanin metabolite protocatechuic acid (PCA) in human clinical trials}

PCA is a major metabolite of BRB anthocyanins, accounting for $70 \%$ of their metabolic breakdown $[39,40]$. It represents a compound of therapeutic significance as compared to BRB anthocyanins as it is relatively stable, commercially available, and inexpensive [41]. Preclinical studies have indicated it too has anti-cancer properties, similar to whole-BRB and the anthocyanins in which PCA is derived from [10, 17]. These therapeutic effects of PCA extend to breast, cervical, liver, and lung cancers [42]. Specifically, PCA demonstrated a similar ability to reduce rat esophageal tumoriogenesis in a carcinogen induced model $[10,17]$. This is presumably due to its effects on inflammation by specifically its ability to reduce expression of COX2, Inducible Nitric Oxide Synthase, active nuclear factor kappa-light-chain-enhancer of activated B cells, and Soluble epoxide hydrolase within the esophagus tissue [10]. This was further demonstrated by the ability of PCA to alter immune cell trafficking, specifically the innate immune cells, within the esophageal tumor microenvironment, similar to whole BRB and their component anthocyanins [17]. As PCA has been reported to remain in human tissues significantly longer than their parent anthocyanins following intake, it is possible that the beneficial effects of BRB anthocyanins are, at least partly, attributed to their metabolite, PCA [42]. The majority of anthocyanin breakdown occurs in the gut by the microbiota, releasing PCA into the systemic circulation [43]. This degradation process can lead to PCA concentration levels that are 8-fold higher than that of their parent anthocyanins [44]. However, differences in one's microbiota can alter the metabolites that are released from BRB anthocyanins, for example some subjects are reported to release gallic acid as the major metabolite [43-45]. Thus, in order to test the clinical relevance of PCA from a cancer therapeutic perspective in human patients, the metabolite itself must be used.

Although PCA is relatively inexpensive and commercially available, new advancements in its extraction method and targeted delivery may facilitate its use in larger clinical trials [39, 46, 47]. Xie et al. have reported a method using imprinted polymers that are attached to the surface of magnetic nanoparticles. Using this method, they were able to successfully isolate PCA from plant extracts including Homalomena occulta and Cynomorium songaricum at recoveries $86-102 \%$ [46]. Thus methods such as this demonstrate the ability to extract large quantities of PCA at high efficiency and purity, facilitating its use in a clinical trial setting. Additionally, the development of enhanced delivery methods of PCA to target tissues may provide a further benefit for its use in clinical trials [48-50]. Saifullah et al. have recently reported the development of a graphene-based nanoparticles that possesses a high affinity for PCA, while also facilitating its release at normal tissue $\mathrm{pH} 7.4$ [48]. Specifically, when the nanoparticles containing PCA were incubated with tumor cell lines including the liver cancer HEP-G2 
cells and colon cancer HT-29 cells, they reported a $40 \%$ release rate of PCA within 8 hours, which grew to almost $80 \%$ within 48 hours [48]. This was associated with a decrease in HEP-G2 cell viability and a lower IC $_{50}$ (45.67 vs. $30.56 \mathrm{ppm}$ ) compared to incubation of these cancer cells with free PCA [48]. This decrease in cancer cell viability was attributed to the sustained release of PCA in culture [48]. Conversely, no significantly difference was shown when incubation of normal fibroblast cells (3T3 cells) with PCA alone or the nanoparticle containing PCA [48]. This again suggests a specificity of PCA for inhibiting cancer cell growth, which is improved by the use of the nanoparticle. Further studies should be conducted in vivo to confirm efficacy of the nanoparticles, but these advancements in PCA extraction and delivery facilitate the use of PCA in human clinical trials [39, 46-50].

\subsection{Improving the targeted delivery of quercetin, a component of BRB, for human trials}

Quercetin is a flavonoid compound that is found in a number of natural products including fruits like BRB, vegetables and teas $[8,51]$. It is categorized as having high antioxidative properties, and tends to only effect the growth of cancer over normal cells [52]. The therapeutic effects of quercetin in cancer are well studied and are thought be through a number of mechanisms. It has been shown to be anti-inflammatory via inhibition of Toll-like receptor signaling [53], it inhibits cancer signaling transduction by modulating microRNA expression [54], and it induces apoptosis by increasing c-Jun N-terminal kinasesignaling [55]. Quercetin is typically a secondary metabolite in fruits and vegetables, however dietary supplements are commercially available and have very low incidence of toxicity [56]. Extracts from BRB containing quercetin can be produced, and have been shown to have anti-cancer properties, however due to the presence of other known flavonoids and polyphenols that inhibit cancer progression, determining whether these effects are due to quercetin in BRB is difficult [57]. The use of imprinted polymers has been shown to have a relatively high efficiency of extracting both quercetin and anthocyanins from the plant mangosteen pericarp, suggesting a potential mechanism for investigating the synergism between anthocyanins and quercetin in human studies [58].

The anti-cancer properties of quercetin are well documented, the hurdle that remains in using it as a cancer therapeutic is insufficient delivery of the compound to the tissue of interest [59,60]. Although quercetin occurs in a number of natural products, its bioavailability is low due to a number of properties including poor water solubility and its rapid body clearance [60]. Recent advances directed at improving the bioavailability of quercetin offer the potential to facilitate its use in human trials. The use of nanoparticles loaded with quercetin alone or with other chemotherapeutics offer some evidence of improved drug delivery to target tissues like the GI tract [61]. Specifically, through the use of silica nanoparticles loaded with quercetin and doxorubicin, a front line chemotherapy in the treatment of gastric cancer [61]. These nanoparticles are designed to be recognized by the CD44 receptor, a marker overexpressed in gastric cancer [61]. In short, use of the nanoparticles in vitro and in vivo displayed selective uptake of doxorubicin and quercetin by gastric cancer cell lines, which correlated with a significant decrease in tumor volume in vivo compared to mice treated with free quercetin plus doxorubicin [61]. Although these findings offer promise in the use of quercetin as a cancer therapeutic, the use of this system only applies to those cancers that overexpress CD44, making their clinical impact relatively limited. However, use of lectin-based dietary formulations of quercetin offer some promise for a more universal use of quercetin as a cancer therapy [62]. Specifically, quercetin alone and quercetin prepared in a lectin-based formulation were prepared and subject to in vitro simulated gastrointestinal fluids and taken in vivo by healthy volunteers, following which levels of quercetin were detected by ultra-performance liquid chromatography [62]. In vitro solubility of quercetin was significantly increased in the lectin-formulation compared to quercetin alone by almost 10-fold in $\mathrm{pH}$ conditions that ranged from 1.6 to 6.5 [62]. Further, the group quantified the quercetin levels within the plasma of healthy volunteers following intake of $500 \mathrm{mg}$ of free quercetin or the lectin-based formulation. They found that within 1 hour, those that took free quercetin had undetectable levels, whereas patients that ingested the lectin-quercetin formula had quercetin levels that reached over $150 \mathrm{ng} / \mathrm{mL}$ and were detectable for over 9 hours following intake [62]. These results not only present a more universal delivery of quercetin in the setting of cancer therapy, but also significantly improve its bioavailability, and thus may improve its therapeutic efficacy. 


\subsection{Ellagic acid as BRB-derived therapeutic in treating human cancer}

Ellagic acid is a phenolic antioxidant that found to be relatively high in human plasma following ingestion of BRB [63]. It has been shown to have anti-cancer effects in esophagus [64], breast [14], colon [65], and oral cancers [66]. These anti-cancer effects may however only account for part of the cancer therapeutic effects of BRB, as oral lesion incidence tends to be lower in a 4-nitroquinoline 1-oxide induced model of animals fed whole BRB compared to those fed ellagic acid alone [66]. Conversely, when BRB are fractionated into their organic soluble anthocyanin-rich fraction and organic insoluble fraction (low anthocyanin content, high ellagic acid content), the insoluble fraction has just as protective in preventing esophageal cancer in a preclinical animal model [27]. Additionally, the anti-estrogenic effects of ellagic acid have proven to be therapeutic in hormone-dependent cancer as well [67]. Thus, the benefits of ellagic acid may be restricted to certain types of cancer.

Although the benefits of ellagic acid in the context of cancer therapy are documented, hurdles remain for its use in human clinical trials. Ellagic acid levels tend to be relatively low compared to other constituents in BRB and other fruits, making their isolation inefficient and the compound itself expensive to produce [8,68]. For example in pomegranate, isolation of ellagic acid by matrix-solid phase dispersion resulted in an ellagic acid yield of less than $1 \%$, with mean recovery approaching $100 \%$ [68]. Further, recent evidence suggests that the anti-cancer benefits of ellagic acid may be due to its major metabolite, urolithin A [67], which is problematic due to the fact that ellagic acid metabolism varies considerably in humans [20,21]. Thus, the benefits of ellagic acid may only extend to those that possess the ideal metabolic machinery to release urolithin A from ellagic acid. Despite these challenges, clinical trials using extracts containing high amounts of ellagic acid have been completed and report mixed effects $[69,70]$. In prostate cancer phase I trial, no significant changes in PSA levels were observed in patients given an extract containing high levels of ellagic acid (produced from muscadine grape) [69]. Conversely in colon cancer patients, beneficial changes in colon cancer-associated gene expression were observed in patients given a pomegranate, ellagic acid containing, extract [70].

\section{Discussion/conclusions}

The ability of plants to prevent and even treat cancer has been well documented [1,2]. Additionally, technology designed to identify the components of these natural products and isolate them for use in preclinical testing has greatly expanded our understanding of mechanistically why plants, specifically BRB, are beneficial in cancer [5-16, 27, 37-39]. This is evident in studies demonstrating the success of BRB-derived fractions that still maintain the beneficial effects of whole BRB [15, 27, 40-47]. More, the use of single components of BRB including anthocyanins, their metabolic PCA products, quercetin, or ellagic acid have demonstrated the ability to inhibit the development and progression of cancer in preclinical models [8, 10, 14, 27]. This has allowed the rationale for their use in clinical trials that are currently underway according to Clinicaltrials.gov. As shown in Table 1, BRB, but also their component anthocyanins, quercetin, and ellagic acid are being used in the treatment of cancer through a variety of delivery methods.

Although the use of these BRB components is beginning to be utilized in a clinical trial setting, obstacles still remain in perfecting these therapeutics. Our ability to isolate content standardized extracts or single agents from BRB appears critical for their potential use in human clinical trials and ultimately as standard cancer therapeutic in a clinical setting. This is due to the high degree of variability that occurs between BRB yields [33] as well as differences in patient metabolism, causing a stratification of patient groups into high, middle and low responders $[20,21]$. Further, lack of bioavailability of specific BRB compounds complicates their use as treatment, even when extraction methods are optimized [36, 37, 44, 45, 60].

New advancements in therapeutic isolation and preparation may offer the key to the use of BRB components in a clinical trial setting. Anthocyanins were historically difficult to quantify and efficiently extract, however advancements in their extraction and tracking in human tissues following intake have greatly improved our 
understanding of their stability and trafficking within the body [33-36]. Additionally, advancements in their preparation, through the use of pectin-based preparations, has allowed for a drastic increase in anthocyanin stability and bioavailability [37]. These results are similar to the development of lectin-based formulations of quercetin, which showed no detectable levels of quercetin in subject plasma just 1 hour after intake, vs. the lectin-based quercetin in which quercetin was detected 9 hours after initial intake [62].

The use of BRB component metabolites vs. their parent compounds may also offer a better option in a clinical trial setting. BRB anthocyanins are predominantly broken down into PCA [39], and PCA has shown to be 8-fold higher in patient tissues compared to anthocyanins [42]. Further PCA has similar effects on preventing to the progression of cancer in preclinical models, similar to whole BRB and their component anthocyanins [10, 17]. Similar trends are seen in ellagic acid, in which its metabolite urolithin A is considered the active anti-cancer component [67]. These findings, coupled with high degrees of variability in patient's ability to utilize these metabolites due to differences in metabolism suggest the use of BRB metabolites as a cancer therapeutic [21].

In conclusion, advancements in BRB component extraction and preparation for human intake have greatly improved in recent years. This has allowed for a standardization of their content while also improving their bioavailability and anti-cancer effects. Further, the use of BRB metabolites, like PCA, may reduce variability in patient response rates due to differences in metabolism. Based on the results of active clinical trials using these components of BRB, attempts should be made to use these newly developed extraction and formulation techniques to perhaps increase the efficacy of these components even more as cancer therapeutics.

\section{Acknowledgments}

A sincere thank you to all clinical trial participants summarized in this review as well as those currently in trials mentioned in Table 1.

\section{References}

[1] World Cancer Research Fund/American Institute for Cancer Research expert report. Food, nutrition, physical activity, and the prevention of cancer: A global perspective. Avaiable at: http://www.aicr.org/assets/docs/pdf/reports/Second_Expert_Report.pdf. 2007.

[2] Turati F, Rossi M, Pelucchi C, Levi F, La Vecchia C. Fruit and vegetables and cancer risk: A review of southern European studies. Br J Nutr. 2015;113(Suppl 2):S102-10. doi:10.1017/S0007114515000148

[3] Bravi F, Edefonti V, Randi G, Ferraroni M, La Vecchia C, Decarli A. Dietary patterns and upper aerodigestive tract cancers: An overview and review. Ann Oncol. 2012;23(12):3024-39. doi:10.1093/annonc/mds197

[4] Norat T, Aune D, Chan D, Romaguera D. Fruits and vegetables: Updating the epidemiologic evidence for the WCRF/AICR lifestyle recommendations for cancer prevention. Cancer Treat Res. 2014;159:35-50. doi:10.1007/978-3-642-38007-5_3

[5] Stoner GD. Foodstuffs for preventing cancer: The preclinical and clinical development of berries. Cancer Prev Res (Phila). 2009;2(3):187-94. doi:10.1158/1940-6207.CAPR-08-0226

[6] Kresty LA, Morse MA, Morgan C, Carlton PS, Lu J, Gupta A, et al. Chemoprevention of esophageal tumorigenesis by dietary administration of lyophilized black raspberries. Cancer Research. 2001;61(16):6112-9.

[7] Lechner JF, Reen RK, Dombkowski AA, Cukovic D, Salagrama S, Wang LS, et al. Effects of a black raspberry diet on gene expression in the rat esophagus. Nutr Cancer. 2008;60(Suppl 1):61-9. doi:10.1080/01635580802393118

[8] Stoner GD, Chen T, Kresty LA, Aziz RM, Reinemann T, Nines R. Protection against esophageal cancer in rodents with lyophilized berries: Potential mechanisms. Nutr Cancer. 2006;54(1):33-46. doi:10.1207/s15327914nc5401_5

[9] Liston BW, Gupta A, Nines R, Carlton PS, Kresty LA, Harris GK, et al. Incidence and effects of Ha-ras codon 12 G->A transition mutations in preneoplastic lesions induced by $\mathrm{N}$-nitrosomethylbenzylamine in the rat esophagus. Molecular carcinogenesis. 2001;32(1):1-8.

[10] Peiffer DS, Zimmerman NP, Wang LS, Ransom BW, Carmella SG, Kuo CT, et al. Chemoprevention of esophageal cancer with black raspberries, their component anthocyanins, and a major anthocyanin metabolite, protocatechuic acid. Cancer Prev Res (Phila). 2014;7(6):574-84. doi:10.1158/1940-6207.CAPR-14-0003 
[11] Harris GK, Gupta A, Nines RG, Kresty LA, Habib SG, Frankel WL, et al. Effects of lyophilized black raspberries on azoxymethane-induced colon cancer and 8-hydroxy-2'-deoxyguanosine levels in the Fischer 344 rat. Nutr Cancer. 2001;40(2):125-33. doi:10.1207/S15327914NC402_8

[12] Wang LS, Kuo CT, Huang TH, Yearsley M, Oshima K, Stoner GD, et al. Black raspberries protectively regulate methylation of Wnt pathway genes in precancerous colon tissue. Cancer Prev Res (Phila). 2013;6(12):1317-27. doi:10.1158/1940-6207.CAPR-13-0077

[13] Casto BC, Kresty LA, Kraly CL, Pearl DK, Knobloch TJ, Schut HA, et al. Chemoprevention of oral cancer by black raspberries. Anticancer Research. 2002;22(6c):4005-15.

[14] Aiyer HS, Gupta RC. Berries and ellagic acid prevent estrogen-induced mammary tumorigenesis by modulating enzymes of estrogen metabolism. Cancer Prev Res (Phila). 2010;3(6):727-37. doi:10.1158/1940-6207.CAPR-09-0260

[15] Duncan FJ, Martin JR, Wulff BC, Stoner GD, Tober KL, Oberyszyn TM, et al. Topical treatment with black raspberry extract reduces cutaneous UVB-induced carcinogenesis and inflammation. Cancer Prev Res (Phila). 2009;2(7):665-72. doi:10.1158/19406207.CAPR-08-0193

[16] Pan P, Peiffer DS, Huang YW, Oshima K, Stoner GD, Wang LS. Inhibition of the development of N-nitrosomethylbenzylamine-induced esophageal tumors in rats by strawberries and aspirin, alone and in combination. J Berry Res. 2018;8(2):137-46. doi:10.3233/JBR170291

[17] Peiffer DS, Wang LS, Zimmerman NP, Ransom BW, Carmella SG, Kuo CT, et al. Dietary Consumption of Black Raspberries or Their Anthocyanin Constituents Alters Innate Immune Cell Trafficking in Esophageal Cancer. Cancer Immunol Res. 2016;4(1):72-82. doi:10.1158/2326-6066.CIR-15-0091

[18] Shumway BS, Kresty LA, Larsen PE, Zwick JC, Lu B, Fields HW, et al. Effects of a topically applied bioadhesive berry gel on loss of heterozygosity indices in premalignant oral lesions. Clin Cancer Res. 2008;14(8):2421-30. doi:10.1158/1078-0432.CCR07-4096

[19] Mallery SR, Zwick JC, Pei P, Tong M, Larsen PE, Shumway BS, et al. Topical application of a bioadhesive black raspberry gel modulates gene expression and reduces cyclooxygenase 2 protein in human premalignant oral lesions. Cancer research. 2008;68(12):4945-57. doi:10.1158/0008-5472.CAN-08-0568

[20] Mallery SR, Tong M, Shumway BS, Curran AE, Larsen PE, Ness GM, et al. Topical application of a mucoadhesive freeze-dried black raspberry gel induces clinical and histologic regression and reduces loss of heterozygosity events in premalignant oral intraepithelial lesions: Results from a multicentered, placebo-controlled clinical trial. Clin Cancer Res. 2014;20(7):1910-24. doi:10.1158/10780432.CCR-13-3159

[21] Kresty LA, Frankel WL, Hammond CD, Baird ME, Mele JM, Stoner GD, et al. Transitioning from preclinical to clinical chemopreventive assessments of lyophilized black raspberries: Interim results show berries modulate markers of oxidative stress in Barrett's esophagus patients. Nutr Cancer. 2006;54(1):148-56. doi:10.1207/s15327914nc5401_15

[22] Kresty LA, Fromkes JJ, Frankel WL, Hammond CD, Seeram NP, Baird M, et al. A phase I pilot study evaluating the beneficial effects of black raspberries in patients with Barrett's esophagus. Oncotarget. 2016;9(82):35356-35372.

[23] Wang LS, Arnold M, Huang YW, Sardo C, Seguin C, Martin E, et al. Modulation of genetic and epigenetic biomarkers of colorectal cancer in humans by black raspberries: A phase I pilot study. Clin Cancer Res. 2011;17(3):598-610. doi:10.1158/1078-0432.CCR$10-1260$

[24] Mentor-Marcel RA, Bobe G, Sardo C, Wang LS, Kuo CT, Stoner G, et al. Plasma cytokines as potential response indicators to dietary freeze-dried black raspberries in colorectal cancer patients. Nutr Cancer. 2012;64(6):820-5. doi:10.1080/01635581.2012.697597

[25] Pan P, Skaer CW, Stirdivant SM, Young MR, Stoner GD, Lechner JF, et al. Beneficial Regulation of Metabolic Profiles by Black Raspberries in Human Colorectal Cancer Patients. Cancer Prev Res (Phila). 2015;8(8):743-50. doi:10.1158/1940-6207.CAPR-15-0065

[26] Wang LS, Burke CA, Hasson H, Kuo CT, Molmenti CL, Seguin C, et al. A phase Ib study of the effects of black raspberries on rectal polyps in patients with familial adenomatous polyposis. Cancer Prev Res (Phila). 2014;7(7):666-74. doi:10.1158/1940-6207.CAPR14-0052

[27] Wang LS, Hecht SS, Carmella SG, Yu N, Larue B, Henry C, et al. Anthocyanins in black raspberries prevent esophageal tumors in rats. Cancer Prev Res (Phila). 2009;2(1):84-93. doi:10.1158/1940-6207.CAPR-08-0155

[28] Miles SL, McFarland M, Niles RM. Molecular and physiological actions of quercetin: Need for clinical trials to assess its benefits in human disease. Nutr Rev. 2014;72(11):720-34. doi:10.1111/nure.12152

[29] Siegel RL, Miller KD, Jemal A. Cancer statistics, 2015. CA Cancer J Clin. 2015;65(1):5-29. doi:10.3322/caac.21254

[30] Stoner GD, Wang LS, Casto BC. Laboratory and clinical studies of cancer chemoprevention by antioxidants in berries. Carcinogenesis. 2008;29(9):1665-74. doi:10.1093/carcin/bgn142

[31] Ma X, Ning S. Cyanidin-3-glucoside attenuates the angiogenesis of breast cancer via inhibiting STAT3/VEGF pathway. Phytother Res. 2018. doi:10.1002/ptr.6201

[32] Kuntz S, Kunz C, Rudloff S. Inhibition of pancreatic cancer cell migration by plasma anthocyanins isolated from healthy volunteers receiving an anthocyanin-rich berry juice. Eur J Nutr. 2017;56(1):203-14. doi:10.1007/s00394-015-1070-3 
[33] Gu J, Ahn-Jarvis JH, Riedl KM, Schwartz SJ, Clinton SK, Vodovotz Y. Characterization of black raspberry functional food products for cancer prevention human clinical trials. J Agric Food Chem. 2014;62(18):3997-4006. doi:10.1021/jf404566p

[34] Giordano L, Coletta W, Tamburrelli C, D’Imperio M, Crescente M, Silvestri C, et al. Four-week ingestion of blood orange juice results in measurable anthocyanin urinary levels but does not affect cellular markers related to cardiovascular risk: A randomized cross-over study in healthy volunteers. Eur J Nutr. 2012;51(5):541-8. doi:10.1007/s00394-011-0237-9

[35] Czank C, Cassidy A, Zhang Q, Morrison DJ, Preston T, Kroon PA, et al. Human metabolism and elimination of the anthocyanin, cyanidin-3-glucoside: A (13)C-tracer study. Am J Clin Nutr. 2013;97(5):995-1003. doi:10.3945/ajcn.112.049247

[36] Manach C, Williamson G, Morand C, Scalbert A, Remesy C. Bioavailability and bioefficacy of polyphenols in humans. I. Review of 97 bioavailability studies. Am J Clin Nutr. 2005;81(1 Suppl):230S-42S. doi:10.1093/ajen/81.1.230S

[37] Yang M, Koo SI, Song WO, Chun OK. Food matrix affecting anthocyanin bioavailability: Review. Current Medicinal Chemistry. 2011;18(2):291-300.

[38] Walton MC, Hendriks WH, Broomfield AM, McGhie TK. Viscous food matrix influences absorption and excretion but not metabolism of blackcurrant anthocyanins in rats. J Food Sci. 2009;74(1):H22-9. doi:10.1111/j.1750-3841.2008.00996.x

[39] Vitaglione P, Donnarumma G, Napolitano A, Galvano F, Gallo A, Scalfi L, et al. Protocatechuic acid is the major human metabolite of cyanidin-glucosides. J Nutr. 2007;137(9):2043-8. doi:10.1093/jn/137.9.2043

[40] Guttenplan JB, Chen KM, Sun YW, Kosinska W, Zhou Y, Kim SA, et al. Effects of Black Raspberry Extract and Protocatechuic Acid on Carcinogen-DNA Adducts and Mutagenesis, and Oxidative Stress in Rat and Human Oral Cells. Cancer Prev Res (Phila). 2016;9(8):704-12. doi:10.1158/1940-6207.CAPR-16-0003

[41] Yin MC, Lin CC, Wu HC, Tsao SM, Hsu CK. Apoptotic effects of protocatechuic acid in human breast, lung, liver, cervix, and prostate cancer cells: Potential mechanisms of action. J Agric Food Chem. 2009;57(14):6468-73. doi:10.1021/jf9004466

[42] Tsuda T, Horio F, Osawa T. Absorption and metabolism of cyanidin 3-O-beta-D-glucoside in rats. FEBS Letters. 1999;449(2-3): 179-82.

[43] Woodward GM, Needs PW, Kay CD. Anthocyanin-derived phenolic acids form glucuronides following simulated gastrointestinal digestion and microsomal glucuronidation. Mol Nutr Food Res. 2011;55(3):378-86. doi:10.1002/mnfr.201000355

[44] Azzini E, Vitaglione P, Intorre F, Napolitano A, Durazzo A, Foddai MS, et al. Bioavailability of strawberry antioxidants in human subjects. Br J Nutr. 2010;104(8):1165-73. doi:10.1017/S000711451000187X

[45] Ferruzzi MG, Lobo JK, Janle EM, Cooper B, Simon JE, Wu QL, et al. Bioavailability of gallic acid and catechins from grape seed polyphenol extract is improved by repeated dosing in rats: Implications for treatment in Alzheimer's disease. J Alzheimers Dis. 2009;18(1):113-24. doi:10.3233/JAD-2009-1135

[46] Xie X, Wei F, Chen L, Wang S. Preparation of molecularly imprinted polymers based on magnetic nanoparticles for the selective extraction of protocatechuic acid from plant extracts. J Sep Sci. 2015;38(6):1046-52. doi:10.1002/jssc.201401142

[47] Li H, Hu X, Zhang Y, Shi S, Jiang X, Chen X. High-capacity magnetic hollow porous molecularly imprinted polymers for specific extraction of protocatechuic acid. J Chromatogr A. 2015;1404:21-7. doi:10.1016/j.chroma.2015.05.038

[48] Saifullah B, Buskaran K, Shaikh RB, Barahuie F, Fakurazi S, Mohd Moklas MA, et al. Graphene Oxide(-)PEG(-)Protocatechuic Acid Nanocomposite Formulation with Improved Anticancer Properties. Nanomaterials (Basel). 2018;8(10). doi:10.3390/nano8100820

[49] Usman MS, Hussein MZ, Kura AU, Fakurazi S, Masarudin MJ, Ahmad Saad FF. Graphene Oxide as a Nanocarrier for a Theranostics Delivery System of Protocatechuic Acid and Gadolinium/Gold Nanoparticles. Molecules. 2018;23(2). doi: $10.3390 /$ molecules23020500

[50] Wang X, Yan K, Ma X, Li W, Chu Y, Guo J, et al. Simultaneous Determination and Pharmacokinetic Study of Protocatechuic Aldehyde and Its Major Active Metabolite Protocatechuic Acid in Rat Plasma by Liquid Chromatography-Tandem Mass Spectrometry. J Chromatogr Sci. 2016;54(5):697-705. doi:10.1093/chromsci/bmv240

[51] Griffiths K, Aggarwal BB, Singh RB, Buttar HS, Wilson D, De Meester F. Food Antioxidants and Their Anti-Inflammatory Properties: A Potential Role in Cardiovascular Diseases and Cancer Prevention. Diseases. 2016;4(3). doi:10.3390/diseases4030028

[52] Rauf A, Imran M, Khan IA, Ur-Rehman M, Gilani SA, Mehmood Z, et al. Anticancer potential of quercetin: A comprehensive review. Phytother Res. 2018;32(11):2109-30. doi:10.1002/ptr.6155

[53] Chen CY, Kao CL, Liu CM. The Cancer Prevention, Anti-Inflammatory and Anti-Oxidation of Bioactive Phytochemicals Targeting the TLR4 Signaling Pathway. Int J Mol Sci. 2018;19(9). doi:10.3390/ijms19092729

[54] Farooqi AA, Jabeen S, Attar R, Yaylim I, Xu B. Quercetin-mediated regulation of signal transduction cascades and microRNAs: Natural weapon against cancer. J Cell Biochem. 2018;119(12):9664-74. doi:10.1002/jcb.27488

[55] Yang Y, Wang T, Chen D, Ma Q, Zheng Y, Liao S, et al. Quercetin preferentially induces apoptosis in KRAS-mutant colorectal cancer cells via JNK signaling pathways. Cell Biol Int. 2018. doi:10.1002/cbin.11055

[56] Andres S, Pevny S, Ziegenhagen R, Bakhiya N, Schafer B, Hirsch-Ernst KI, et al. Safety Aspects of the Use of Quercetin as a Dietary Supplement. Mol Nutr Food Res. 2018;62(1). doi:10.1002/mnfr.201700447 
[57] Paudel L, Wyzgoski FJ, Giusti MM, Johnson JL, Rinaldi PL, Scheerens JC, et al. NMR-based metabolomic investigation of bioactivity of chemical constituents in black raspberry (Rubus occidentalis L.) fruit extracts. J Agric Food Chem. 2014;62(8):1989-98. doi:10.1021/jf404998k

[58] Piacham T, Isarankura-Na-Ayudhya C, Prachayasittikul V. Quercetin-imprinted polymer for anthocyanin extraction from mangosteen pericarp. Mater Sci Eng C Mater Biol Appl. 2015;51:127-31. doi:10.1016/j.msec.2015.02.051

[59] Massi A, Bortolini O, Ragno D, Bernardi T, Sacchetti G, Tacchini M, et al. Research Progress in the Modification of Quercetin Leading to Anticancer Agents. Molecules. 2017;22(8). doi:10.3390/molecules22081270

[60] Kaşikci MB, Bağdatlioğlu N. Bioavailability of quercetin. Current Research in Nutrition and Food Science Journal. 2016;4(Special Issue Nutrition in Conference October 2016):146-51. doi:10.12944/CRNFSJ.4.Special-Issue-October.20

[61] Fang J, Zhang S, Xue X, Zhu X, Song S, Wang B, et al. Quercetin and doxorubicin co-delivery using mesoporous silica nanoparticles enhance the efficacy of gastric carcinoma chemotherapy. Int J Nanomedicine. 2018; 13:5113-26. doi:10.2147/IJN.S170862

[62] Riva A, Ronchi M, Petrangolini G, Bosisio S, Allegrini P. Improved Oral Absorption of Quercetin from Quercetin Phytosome(R), a New Delivery System Based on Food Grade Lecithin. Eur J Drug Metab Pharmacokinet. 2018. doi:10.1007/s13318-018-0517-3

[63] Stoner GD, Sardo C, Apseloff G, Mullet D, Wargo W, Pound V, et al. Pharmacokinetics of anthocyanins and ellagic acid in healthy volunteers fed freeze-dried black raspberries daily for 7 days. J Clin Pharmacol. 2005;45(10):1153-64. doi:10.1177/0091270005279636

[64] de Boer JG, Yang H, Holcroft J, Skov K. Chemoprotection against N-nitrosomethylbenzylamine-induced mutation in the rat esophagus. Nutr Cancer. 2004;50(2):168-73. doi:10.1207/s15327914nc5002_6

[65] Cho H, Jung H, Lee H, Yi HC, Kwak HK, Hwang KT. Chemopreventive activity of ellagitannins and their derivatives from black raspberry seeds on HT-29 colon cancer cells. Food Funct. 2015;6(5):1675-83. doi:10.1039/c5fo00274e

[66] Oghumu S, Casto BC, Ahn-Jarvis J, Weghorst LC, Maloney J, Geuy P, et al. Inhibition of Pro-inflammatory and Anti-apoptotic Biomarkers during Experimental Oral Cancer Chemoprevention by Dietary Black Raspberries. Front Immunol. 2017;8:1325. doi:10.3389/fimmu.2017.01325

[67] Larrosa M, Gonzalez-Sarrias A, Garcia-Conesa MT, Tomas-Barberan FA, Espin JC. Urolithins, ellagic acid-derived metabolites produced by human colonic microflora, exhibit estrogenic and antiestrogenic activities. J Agric Food Chem. 2006;54(5):1611-20. doi:10.1021/jf0527403

[68] Kamal YT, Alam P, Alqasoumi SI, Foudah AI, Alqarni MH, Yusufoglu HS. Investigation of antioxidant compounds in commercial pomegranate molasses products using matrix-solid phase dispersion extraction coupled with HPLC. Saudi Pharm J. 2018;26(6):839-44. doi:10.1016/j.jsps.2018.03.015

[69] Paller CJ, Rudek MA, Zhou XC, Wagner WD, Hudson TS, Anders N, et al. A phase I study of muscadine grape skin extract in men with biochemically recurrent prostate cancer: Safety, tolerability, and dose determination. Prostate. 2015;75(14):1518-25. doi:10.1002/pros.23024

[70] Nunez-Sanchez MA, Gonzalez-Sarrias A, Garcia-Villalba R, Monedero-Saiz T, Garcia-Talavera NV, Gomez-Sanchez MB, et al. Gene expression changes in colon tissues from colorectal cancer patients following the intake of an ellagitannin-containing pomegranate extract: A randomized clinical trial. J Nutr Biochem. 2017;42:126-33. doi:10.1016/j.jnutbio.2017.01.014 